\title{
FAME Production from Jatropha Curcas seed oil via Calcium Oxide Catalyzed Transesterification and its Purification using Acid Activated Bentonite
}

\author{
Novizar Nazir", Sri Yuliani* \\ \# Faculty of Agricultural Technology, Andalas University. Kampus Limau Manis. Padang.Indonesia \\ E-mail:nazir_novizar@yahoo.com \\ * The Indonesian Center for Agricultural Postharvest Research and Development, Bogor, Indonesia \\ E-mail: yuliani@gmail.com
}

\begin{abstract}
This paper presents the study of transesterification of Jatropha curcas oil (JCO) via environmentally benign process using calcium oxide as heterogeneous catalyst. Response surface methodology (RSM) based on central composite design (CCD) was performed to optimize three reaction variables in this study. The transesterification process variables were reaction time, $x 1(60$ minutes-120 minutes), molar ratio of methanol: oil, x2 (5:1 - 13:1), and amount of catalyst, $x 3(0.5 \%-1.50 \%$ of mass fraction). Since water washing method is not suitable to purify $\mathrm{CaO}$ synthesized fatty acid methyl esters (FAME), the purification of assynthesized FAME with acid-activated bentonites to eliminate the remaining calcium was also investigated. It was found that the yield of JCO FAME could reach up to $94.35 \%$ using the following reaction conditions: 79.33 minutes reaction time, 10.41:1 methanol:oil molar ratio and $0.99 \%$ catalyst at reaction temperature $650 \mathrm{C}$. Among bentonites used in the purification, $2.5 \%$ of H2SO4-activated bentonite shows a good performance as decalcifying agent for FAME purification. The properties of purified jatropha FAME were comparable to those of diesel and satisfied the international standard.
\end{abstract}

Keywords-FAME; biodiesel; Jatropha curcas; transesterification; bentonite purification; calcium oxide; heterogeneous catalyst

\section{INTRODUCTION}

Biodiesel has been widely accepted as an alternative energy source. It is very popular due to its renewable, nontoxic, biodegradable and non-flammable properties besides its low emission profiles and environmentally beneficial characteristics. Biodiesel can be used either in a pure form or as blends on conventional petro-diesel in automobiles without any major engine modifications [1-5]. There are various non-edible and edible oils which can be used for as alternative source for engine fuel. However, the use of nonedible oil is preferable since it is inapplicable as a food source. Among the non-edible oils, J. curcas has remarkable potentials for biodiesel production [6].

The production of biodiesel or more commonly known as FAME can be classified into homogeneous, heterogeneous and non-catalytic methods, depending upon the type of catalyst used in the process. Traditionally, homogeneous method is used in many commercial production of FAME. However, this method has many disadvantages. In this method, the reactants, catalyst and FAME are all in the liquid phase. This results in a complex liquid-liquid separation process. Besides, the recovery of the homogenous catalyst is also difficult, thus resulting in loss of useful material. Moreover, the catalyst dissolves fully in the glycerin layer and partially in the FAME layer. This makes FAME need to be cleaned through a slow, tedious and an environmentally unfriendly water washing process. In addition, catalyst contaminated glycerin has little value in today's market and is increasingly becoming a disposal issue [7]. In contrast, heterogeneous transesterification method proved to be more superior as compared to the homogenous transesterification method especially on the separation and purification of the product (FAME) [8-11]. The heterogeneous method, which uses solid catalyst, does not face the same limitations. Solid-liquid separation process is relatively easy as compared to liquid-liquid separation process. This makes the recovery of solid catalyst a lot easier.

In addition, heterogeneous catalyzed method eliminates the formation of soap. This omits the need of wash water. Elimination in the formation of soap then prevents the formation of emulsion which could complicate the separation and purification processes in the mixture [12]. Recently, there are many feasible heterogeneous catalysts 
suitable for transesterification process. Among them are metal oxides [13-17], metal complexes [18], active metals loaded on supports [19,20], zeolite [21], resins [22,23], membranes [24,25], lipases [26], and hydrotalcites [27]. Some of these catalysts are already used in commercial production of FAME and patented [28]. They have been proven to have high activity in the reaction of transesterification. Among alkalic heterogeneous catalysts, $\mathrm{CaO}$ is one of the most investigated compounds because of its high basicity, low solubility, low price, and possibility of production from cheap sources. Moreover, it is easier to handle than homogeneous catalyst such as $\mathrm{KOH}$ or $\mathrm{NaOH}$ $[29,30]$.

There has been various experiments on $\mathrm{CaO}$ catalyzed transesterification. Most of these catalysts, however, are used on oils such as soybean oil [31-34], sunflower oil [16,35-37], rapeseed oil [38-40] and microalgae [41]. A single case of using $\mathrm{CaO}$ catalyst on JCO transesterification was reported by Zhu [29]. But, the catalyst must be treated with ammonium carbonate before calcinations at high temperature. Thus, the main objective of this study is application of $\mathrm{CaO}$ without ammonium carbonate treatment as heterogeneous catalyst to optimize the production of fatty acid methyl esters (FAME) from JCO.

This study is supplemented by a statistical design of experiment using response surface methodology (RSM). It is used to accumulate and analyze information on the effect of three process variables on the yield of transesterification in a rapid and efficient manner using minimum number of experiments. As water washing method is not suitable for purifying CaO-treatment [29], the procedure employing the acid-activated bentonites was also investigated. It is expected that FAME production process will be simple, low cost, and environmentally friendly.

\section{MATERIALS AND METHODS}

\section{A. Materials}

Mature seeds of J. curcas were collected from South Lampung District, Lampung Province, Indonesia (LN 5 29', LO105 30 ', $120 \mathrm{~m}$ above sea level, annual rainfall 2500 $\mathrm{mm}$, soil type: inseptisol). The seeds were selected in such a way that, the damaged seeds were discarded and the seeds in good condition were cleaned, de-shelled and sundried and dried at a temperature of $70{ }^{\circ} \mathrm{C}$ for $24 \mathrm{~h}$ before pressing using hydraulic jack press. The oil extraction was carried out at room temperature and oil was stored in the ice room at $-5{ }^{\circ} \mathrm{C}$ until needed for analysis. The seed cakes, by-product of oil extraction, was sun-dryed and stored in the ice room at $-5^{\circ} \mathrm{C}$ until needed for further studies on toxicity.

Fatty acid composition of JCO are given in Table 1. Anhydrous methanol (MeOH), 99.8\%; potassium hydroxide $(\mathrm{KOH})$, sulfuric acid $\left(\mathrm{H}_{2} \mathrm{SO}_{4}\right)$, and $37 \%-38 \%$ hydrochloric acid $(\mathrm{HCl})$, were purchased from ChemAR ${ }^{\circledR}$. A calciumrich bentonite $(\mathrm{CaB})$ sample was obtained as powder from PT. Superintending Company of Indonesia. Chemical composition of bentonite are: $\mathrm{SiO}_{2}(64.15 \%)$; $\mathrm{TiO}_{2}(0.47 \%)$; $\mathrm{CrO}_{3}(0.003 \%) ; \mathrm{Al}_{2} \mathrm{O}_{3}(0.70 \%) ; \mathrm{Fe}_{2} \mathrm{O}_{3}(0.10 \%) ; \mathrm{MgO}$ $(0.70 \%) ; \mathrm{CaO}(0.03 \%) ; \mathrm{Na}_{2} \mathrm{O}(0.20 \%) ; \mathrm{K}_{2} \mathrm{O}(0.50 \%)$ and $22.61 \%$ of loss on ignition (LOI). The pulverized limestone $\left(\mathrm{CaCO}_{3}\right)$ as a source of $\mathrm{CaO}$ was obtained from Sago
Halaban, West Sumatra-Indonesia (LN 0 ${ }^{\circ} 16^{\prime}, \mathrm{LO}^{\circ} 100^{\circ} 42^{\prime}$, $676 \mathrm{~m}$ above sea level). Elemental composition analysis with ED-2000 XRF spectrometer indicated that the limestone contained $\mathrm{CaO}(54.85 \%), \mathrm{Fe}_{2} \mathrm{O}_{3}(0.32 \%), \mathrm{MgO}$ (0.65\%), $\mathrm{SiO}_{2}(2.46 \%), \mathrm{Al}_{2} \mathrm{O}_{3}(0.31 \%)$, and LOI (43.8\%).

TABLE I

FATTY ACID COMPOSITION OF JATROPHA OIL

\begin{tabular}{|l|l|l|l|r|}
\hline $\begin{array}{l}\text { Acid } \\
\text { Common } \\
\text { Name }\end{array}$ & Formula & Structure & Systemic name & $\begin{array}{r}\text { Percentage } \\
(\%)\end{array}$ \\
\hline Palmitic & $\mathrm{C}_{16} \mathrm{H}_{32} \mathrm{O}_{2}$ & $\mathrm{C} 16: 0$ & Hexadecanoic & 14.07 \\
\hline Palmitoleic & $\mathrm{C}_{16} \mathrm{H}_{30} \mathrm{O}_{2}$ & $\mathrm{C} 16: 1$ & $\begin{array}{l}\text { Cis-9- } \\
\text { Hexadecanoic }\end{array}$ & 0.94 \\
\hline Stearic & $\mathrm{C}_{18} \mathrm{H}_{36} \mathrm{O}_{2}$ & $\mathrm{C} 18: 0$ & Octadecanoic & 6.03 \\
\hline Oleic & $\mathrm{C}_{18} \mathrm{H}_{34} \mathrm{O}_{2}$ & $\mathrm{C} 18: 1$ & $\begin{array}{l}\text { Cis-9- } \\
\text { Hexadecanoic }\end{array}$ & 43.55 \\
\hline Linoleic & $\mathrm{C}_{18} \mathrm{H}_{32} \mathrm{O}_{2}$ & $\mathrm{C} 18: 2$ & $\begin{array}{l}\text { cis-9,cis-12- } \\
\text { Octadecedianoic }\end{array}$ & 34.50 \\
\hline
\end{tabular}

\section{B. Preparation of $\mathrm{CaO}$ catalyst}

The $\mathrm{CaO}$ catalyst (in powder form) was prepared by calcination of pulverized lime stone $\left(\mathrm{CaCO}_{3}\right)$ for $1.5 \mathrm{~h}$, at $900^{\circ} \mathrm{C}[32] . \quad \mathrm{CaO}$ was stored under vacuum in desiccator that contains silica gel and $\mathrm{KOH}$ pellets to remove $\mathrm{H}_{2} \mathrm{O}$ and $\mathrm{CO}_{2}$ of residual atmosphere. Before it was used, $\mathrm{CaO}$ was pretreated by outgassing at $700^{\circ} \mathrm{C}$ [35] for 30 minutes. The properties of $\mathrm{CaO}$ compared to those of $\mathrm{CaCO}_{3}$ as a source of $\mathrm{CaO}$ catalyst are summarized in Table 2 .

TABLE III

PROPERTIES OF THE CAO CATALYSTS IN COMPARISON TO THOSE OF CACO3

\begin{tabular}{|l|l|l|}
\hline & $\begin{array}{l}\text { BET surface } \text { area }^{\mathrm{a}} \\
\left(\mathrm{m}^{2} / \mathrm{g}\right)\end{array}$ & Basic strength $^{\mathrm{b}}\left(\mathrm{H}_{-}\right)$ \\
\hline $\mathrm{CaO}$ & 13 & $15.0<\mathrm{H}_{-}<18.4$ \\
\hline $\mathrm{CaCO}_{3}$ & 10 & $7.2<\mathrm{H}_{-}<9.3$ \\
\hline
\end{tabular}

${ }^{\mathrm{a}}$ Calculated by BET method on the data from adsorption of nitrogen

${ }^{\mathrm{b}}$ Determined by using Hammett indicators

\section{Preparation of acid activated bentonite adsorbent}

Acid activated Bentonite were prepared by aqueous impregnation technique. Either $5.3 \mathrm{kmol} \mathrm{m}^{-3}$ aqueous solution of $\mathrm{HCl}$ or $400 \mathrm{~kg} \mathrm{~m}^{-3}$ of aqueous solution of $\mathrm{H}_{2} \mathrm{SO}_{4}$ was applied to bentonite by aqueous impregnation (at $80{ }^{\circ} \mathrm{C}$ and $4 \mathrm{~h}$ ). The material was washed with deionized water until $\mathrm{Cl}^{-1}$ and $\mathrm{SO}_{4}^{-2}$ ions were not detected. Then, it was dried overnight and calcinated at $500{ }^{\circ} \mathrm{C}$ for three hours. The surface area of bentonite was measured with multipoint Brunauer, Emmett and Teller (BET) method from the Quantachrome Surface Analysis Instrument (Autosorb 1-C, Boynton Beach, Florida, USA). This was done using nitrogen adsorption/desorption isotherms at liquid nitrogen temperature and relative pressures $(\mathrm{P} / \mathrm{Po})$ ranging from $0.04-$ 0.40 , where a linear relationship was maintained.

Five adsorbents for decalcination of as synthesized FAME were used, they were: (A) "untreated" bentonite; (B) 5.3 $\mathrm{kmol} \mathrm{m} \mathrm{m}^{-3}$ aqueous solution of $\mathrm{HCl}$-activated bentonite; (C) $5.3 \mathrm{kmol} \mathrm{m}^{-3}$ aqueous solution of $\mathrm{HCl}$-activated and calcinated at $500{ }^{\circ} \mathrm{C}$ bentonite; (D) $400 \mathrm{~kg} \mathrm{~m}^{-3}$ of aqueous solution of $\mathrm{H}_{2} \mathrm{SO}_{4}$-activated bentonite; (E) $400 \mathrm{~kg} \mathrm{~m}^{-3}$ of aqueous solution of $\mathrm{H}_{2} \mathrm{SO}_{4}$-activated and calcinated at 500 
${ }^{\circ} \mathrm{C}$ bentonite. Physical parameters of bentonite and acidactivated bentonites is shown in Table 3 .

TABLE IIIII

PHYSICAL PARAMETERS OF BENTONITE AND ACID-ACTIVATED BENTONITES.

\begin{tabular}{|l|c|c|c|c|c|}
\hline \multirow{2}{*}{$\begin{array}{l}\text { Physical } \\
\text { parameter }\end{array}$} & \multicolumn{5}{|c|}{ Adsorbent } \\
\cline { 2 - 6 } $\begin{array}{l}\text { BET surface } \\
\text { area }\left(\mathrm{m}^{2} / \mathrm{g}\right)\end{array}$ & 50.6496 & 239.3534 & 210.1829 & 252.2536 & 248.3601 \\
\hline $\begin{array}{l}\text { Langmuir } \\
\text { surface } \\
\text { area(m } / \mathrm{g})\end{array}$ & 79.1939 & 374.8640 & 329.6299 & 393.8833 & 389.3721 \\
\hline $\begin{array}{l}\text { External } \\
\text { surface area } \\
\left(\mathrm{m}^{2} / \mathrm{g}\right)\end{array}$ & 46.6242 & 226.2408 & 199.0738 & 232.8391 & 233.6701 \\
\hline $\begin{array}{l}\text { Micropore area } \\
\left(\mathrm{m}^{2} / \mathrm{g}\right)\end{array}$ & 4.0254 & 13.1128 & 11.0990 & 19.4145 & 14.6900 \\
\hline $\begin{array}{l}\text { Micropore } \\
\text { volume }\left(\mathrm{m}^{3} / \mathrm{g}\right)\end{array}$ & 0.0018 & 0.0052 & 0.0044 & 0.0085 & 0.0060 \\
\hline
\end{tabular}

\section{Evaluation of catalytic activity of $\mathrm{CaO}$ catalyst}

1) FFA removal by esterification : Jatropha curcas oil with high content of FFAs cannot be directly used in an alkali catalyzed transesterification because FFAs will react with alkali catalyst to form soaps, which result in serious emulsification and separation problem. Esterification catalyzed by homogeneous acids, such as sulphuric acid, phosporic acid, or sulphonic acid, is a conventionally used method to reduce the FFAs. This makes possible transesterification of raw oils by an alkalic catalyst $[39,40]$. FFA removal in this study was done by esterification reaction using the method of Tiwari et al [42]. At a constant stirring rate $3.3 \mathrm{~Hz}, 200 \mathrm{ml}$ of jatropha oil was pretreated with $280 \mathrm{dm} 3 \mathrm{~m}-3$ solution of methanol using $1.43 \%$ volume fraction of $\mathrm{H} 2 \mathrm{SO} 4$ as a catalyst in 88 mins reaction time, and reaction at $60{ }^{\circ} \mathrm{C}$.

2) Level-2 Heading: The $\mathrm{CaO}$ catalyst and methanol were added into a $250 \mathrm{ml}$ three-neck flask and stirred for 20 mins. Then, the temperature was raised to the desired level reaction temperature $\left(65^{\circ} \mathrm{C}\right)$. Subsequently, $30 \mathrm{~g}$ of JCO was added through a constant press dropper. After the reaction, the solid catalyst was separated by centrifugation using Compact Tabletop Centrifuge 2420 (Kubota Corporation, Japan). The liquid was put into a separating funnel and was kept at ambient temperature for 4 hours. Afterwards, two liquid phases appeared: the upper layer was FAME and the lower was glycerol. Synthesized FAME was purified before analysis. The analysis of FAME for each sample was carried out by dissolving $1.0 \mathrm{~g}$ of FAME sample and $0.2 \mathrm{~g}$ of methyl salicylate which was added as a reference into $8 \mathrm{~mL}$ of $\mathrm{n}$-hexane and injecting $1 \mu \mathrm{L}$ of this solution in the Shimadzu-GC17A Gas Chromatograph, Japan. The sample injected was separated in a BPX 70 capillary column $(30 \mathrm{~m} \times 0.25 \mathrm{~mm} \times 0.25 \mu \mathrm{m})$ and a flame ionization detector (FID). The oven temperature of the GC was programmed $180^{\circ} \mathrm{C}$ (isothermal) for $15 \mathrm{~min}$. The injector's and detector's temperatures were $280^{\circ} \mathrm{C}$ and $250{ }^{\circ} \mathrm{C}$ respectively. The purity of FAME samples was calculated based on the area of FAME over the reference by the following equation:

Purity $(\%)=\frac{(\text { area of FAME)/area of reference) } x \text { (weight of reference) })}{\text { Weight of FAME sample }} \times 100 \ldots \ldots \ldots$

\section{E. Purification of the as-synthesized FAME}

Twenty milliliters of as-synthesized FAME followed by the adsorbent were added into a $50 \mathrm{ml}$ conical flask, and the mixture was stirred for $15 \mathrm{~min}$. The product was centrifuged at $50 \mathrm{~Hz}$ for 10 mins. As a result, purified FAME appeared at the upper layer.

The quantity of calcium ions that remained in the FAME was analyzed using spectrophotometric method. Less than $0.5 \mathrm{~g}$ FAME sample was digested with hydrogen peroxide and nitric acid using MLS-120 Mega Microwave for 18 mins. The samples then were analyzed with $A A S / I C P-O E S / I C P$ $M S$ (GBC 906 Elite).

The performance of the adsorbent was evaluated by determining the change in concentration of the calcium ions in FAME before and after the decalcification. The decalcification efficiency and FAME yield were calculated using the equations:

Decalcification efficiency $=1-($ remaining calcium ions $/$ total calcium ions) $\times 100 \%$.

and,

Yield $=$ (volume of the refined FAME / volume of the synthesized FAME) $\times 100 \%$.......

Six methods for the purification step in FAME production were compared: (A) adsorption on "untreated" bentonite; (B) adsorption on $\mathrm{HCl}$-activated bentonite; (C) adsorption with $\mathrm{HCl}$-activated and calcinated at $500{ }^{\circ} \mathrm{C}$ bentonite (D) adsorption on $\mathrm{H}_{2} \mathrm{SO}_{4}$-activated bentonite; (E) adsorption on $\mathrm{H}_{2} \mathrm{SO}_{4}$-activated and calcinated at $500{ }^{\circ} \mathrm{C}$ bentonite; and (F) citric acid, as a control treatment.

\section{F. Fuel properties}

The fuel properties namely density, kinematic viscosity, flash point, cetane number, and acid value of jatropha oil, jatropha FAME and conventional diesel were determined according to the recommended methods and compared with the latest American and European standards [29].

\section{$G$. The design of the experiments}

The experimental design selected for this study is a central composite design (CCD) that helps in investigating linear, quadratic, cubic and cross-product effects of the three transesterification process variables (independent) on the conversion of JCO FAME (response). The three transesterification process variables studied are reaction period, ratio of oil to methanol and amount of catalyst. Table 4 lists the range and levels of the three independent variables studied. The complete design matrix of the experiments employed and results are given in Table 5.

TABLE IVV

INDEPENDENT VARIABLES AND LEVELS USED FOR CCD IN TRANSESTERIFICATION

\begin{tabular}{|c|c|c|c|c|c|c|c|}
\hline \multirow[t]{2}{*}{ Variable } & \multirow[t]{2}{*}{ Coding } & \multirow[t]{2}{*}{ Unit } & \multicolumn{5}{|c|}{ Levels } \\
\hline & & & $-\alpha$ & -1 & 0 & +1 & $+\alpha$ \\
\hline $\begin{array}{l}\text { Reaction } \\
\text { time }\end{array}$ & $\mathrm{X}_{1}$ & $\min$ & 60 & 75 & 90 & 115 & 120 \\
\hline $\begin{array}{l}\text { Molar Ratio } \\
\text { of } \\
\text { Methanol/oil }\end{array}$ & $\mathrm{X}_{2}$ & $\begin{array}{l}\mathrm{mol} \\
\mathrm{mol}^{-1}\end{array}$ & $5: 1$ & $7: 1$ & $9: 1$ & $11: 1$ & $13: 1$ \\
\hline $\begin{array}{l}\text { Mass fraction } \\
\text { of catalyst }\end{array}$ & $\mathrm{X}_{3}$ & $\%$ & 0.50 & 0.75 & 1 & 1.25 & 1.50 \\
\hline
\end{tabular}


TABLE V

CCD ARRANGEMENT AND RESPONSES FOR TRANSESTERIFICATION PROCESS.

\begin{tabular}{|c|c|c|c|c|c|c|c|}
\hline \multirow[t]{2}{*}{ No } & \multirow[t]{2}{*}{ Random } & \multirow[t]{2}{*}{$\begin{array}{l}\text { Point } \\
\text { Type }\end{array}$} & \multicolumn{3}{|c|}{ Levels of variables } & \multicolumn{2}{|c|}{$\begin{array}{l}\text { Conversion } \\
(\%)\end{array}$} \\
\hline & & & $\begin{array}{l}\text { Reaction } \\
\text { time } \\
\text { (mins) }\end{array}$ & $\begin{array}{r}\text { Ratio of } \\
\text { Methanol/ } \\
\text { Oil }(\mathrm{mol} \\
\left.\mathrm{mol}^{-1}\right)\end{array}$ & $\begin{array}{l}\text { Mass } \\
\text { fraction of } \\
\text { catalyst } \\
(\%)\end{array}$ & $\begin{array}{l}\text { Expe } \\
\text { rimen } \\
\text { tal }\end{array}$ & $\begin{array}{l}\text { Predic } \\
\text { ted }\end{array}$ \\
\hline 1 & 8 & Fact & $(-1) 75$ & $(-1) 7: 1$ & $(-1) 0.75$ & 86.12 & 82.24 \\
\hline 2 & 16 & Fact & $(+1) 115$ & $(-1) 7: 1$ & $(-1) 0.75$ & 80.92 & 76.60 \\
\hline 3 & 4 & Fact & $(-1) 75$ & $(+1) 13: 1$ & $(-1) 0.75$ & 89.67 & 88.71 \\
\hline 4 & 11 & Fact & $(+1) 115$ & $(+1) 13: 1$ & $(-1) 0.75$ & 80.76 & 82.82 \\
\hline 5 & 9 & Fact & $(-1) 75$ & $(-1) 7: 1$ & $(+1) 1.25$ & 36.21 & 40.91 \\
\hline 6 & 18 & Fact & $(+1) 115$ & $(-1) 7: 1$ & $(+1) 1.25$ & 36.68 & 44.40 \\
\hline 7 & 13 & Fact & $(-1) 75$ & $(+1) 11: 1$ & $(+1) 1.25$ & 79.71 & 90.79 \\
\hline 8 & 19 & Fact & $(+1) 115$ & \begin{tabular}{|l|}
$(+1) 11: 1$ \\
\end{tabular} & $(+1) 1.25$ & 83.40 & 94.04 \\
\hline 9 & 20 & Axial & $(-\alpha) 60$ & (0)9:1 & $(0) 1.00$ & 87.33 & 85.24 \\
\hline 10 & 17 & Axial & $(+\alpha) 120$ & (0)9:1 & $(0) 1.00$ & 87.51 & 82.84 \\
\hline 11 & 14 & Axial & (0)90 & $(-\alpha) 5: 1$ & $(0) 1.00$ & 22.62 & 23.89 \\
\hline 12 & 7 & Axial & $(0) 90$ & $(+\alpha) 13: 1$ & (0)1.00 & 88.03 & 80.00 \\
\hline 13 & 1 & Axial & (0)90 & (0)9:1 & $(-\alpha) 0.50$ & 83.17 & 90.00 \\
\hline 14 & 6 & Axial & (0)90 & (0)9:1 & $(+\alpha) 1.50$ & 73.67 & 59.98 \\
\hline 15 & 3 & Center & (0)90 & $(0) 9: 1$ & (0)1.00 & 90.16 & 89.24 \\
\hline 16 & 10 & Center & (0)90 & (0)9:1 & $(0) 1.00$ & 92.01 & 89.24 \\
\hline 17 & 2 & Center & (0)90 & (0)9:1 & (0)1.00 & 89.20 & 89.24 \\
\hline 18 & 12 & Center & (0)90 & (0)9:1 & (0)1.00 & 90.21 & 89.24 \\
\hline 19 & 15 & Center & $(0) 90$ & $(0) 9: 1$ & (0)1.00 & 89.75 & 89.24 \\
\hline 20 & 5 & Center & (0)90 & (0)9:1 & (0)1.00 & 90.89 & 89.24 \\
\hline
\end{tabular}

Each response of the transesterification process was used to develop a mathematical model that correlates the conversion of JCO FAME to the transesterification process variables studied through first order, second order and interaction terms, according to the following second order polynomial equation,

$$
\mathrm{y}=\beta 0+\sum_{j=1}^{3} \beta j x j+\sum_{\substack{i j \\ \beta_{i j=1}}}^{3} X_{i} X_{j}+\sum \beta_{j i j}^{3} x_{j}^{2+} e_{1} \ldots \ldots \ldots \ldots \ldots
$$

where $\mathrm{y}$ is the predicted conversion of JCO FAME; $x_{i}$ and $x_{j}$ represent the variables; $\beta_{\mathrm{o}}$ is a constant coefficient; $\beta_{\mathrm{j}}$ is the linear effect; $\beta_{\mathrm{ij}}$ is first order interaction effect; $\beta_{\mathrm{jj}}$ is a squared effect and $\mathrm{e}_{1}$ is the error.

\section{H. Model fitting and statistical analysis}

Design Expert software version 6.0.6 (STAT-Ease Inc., Minneapolis, USA) was used for regression analysis of the experimental data to fit the second order polynomial equation and also for evaluation of the statistical significance of the equation developed.

\section{RESULTS AND DISCUSSION}

\section{A. Development of regression model equation}

The final equation in terms of uncoded (actual) factors for conversion of JCO FAME is,

$$
\begin{aligned}
& \text { Conversion }(\%)=15.87+0.41 * \mathrm{x}_{1}+27.45^{*} \mathrm{x}_{2}-166.66 * \mathrm{x}_{3}-5.78 \mathrm{E}^{-003} \\
& * \mathrm{x}_{1}^{2}-2.33 * \mathrm{x}_{2}^{2}-56.82 * \mathrm{x}_{3}^{2}-2.04 \mathrm{E}^{-003} * \mathrm{x}_{1} * \mathrm{x}_{2} \\
& +0.61 * \mathrm{x}_{1} * \mathrm{x} 3+21.71 * \mathrm{x}_{2} * \mathrm{x}_{3} \text {, with } \mathrm{R}^{2}=95.56
\end{aligned}
$$

Positive sign in front of the terms indicates synergistic effect, while negative sign indicates antagonistic effect. Eq. (5) shows that the yield of JCO FAME has a linear and quadratic effect on the three transesterification process variables studied. High $R^{2}$ value illustrates good agreement between the calculated and observed results within the range of experiment. The optimized critical values were found to be 79.33 minutes reaction time, 10.41:1 methanol:oil molar ratio and $0.99 \%$ catalyst at reaction temperature $65^{\circ} \mathrm{C}$. It was found that the conversion of JCO oil to FAME could reach up to $94.35 \%$ in this optimized conditions.

Fig.1 shows the experimental values versus predicted values using the model equation developed. A line with the slope of 1 , which corresponds to a perfect fit with zero deviation from the experimental points, is also shown. This plot therefore visualizes the performance of the model in an obvious way. The results in Fig.1 demonstrate that the regression model equation describes the experimental data with sufficient accuracy, indicating that it was successful in capturing the correlation between the four transesterification process variables to the yield of JCO FAME.

\section{B. Effects of transesterification process variables}

Data from the reaction experiment of Kouzu et al [33] gain the yield of FAME catalyzed by $\mathrm{CaCO}_{3}$ was less than $10 \%$ at $4 \mathrm{~h}$ of the reaction time. This yield indicated that $\mathrm{CaCO}_{3}$ seemed to be ineffective in catalyzing the transesterification [33]. It was evident that the decrease in the catalytic activity was corresponded to that of the basic properties and BET surface area, as shown in Table 2 [34].

As can be seen from Table 6 , the model $F$-value of 11.67 and a low probability value $(\mathrm{P}>F<0.0001)$ indicate that the model was significant for predicting the conversion of FAME from $J$. curcas oil. It was observed that among the three individual variables studied, the molar ratio of methanol/oil $\left(\mathrm{x}_{2}\right)$ has the largest effect on the yield of JCO FAME (due to the highest $F$ value) followed by the amount of catalyst $\left(\mathrm{x}_{3}\right)$ whereas the reaction time $\left(\mathrm{x}_{1}\right)$ has otherwise insignificant effect (Table 6).

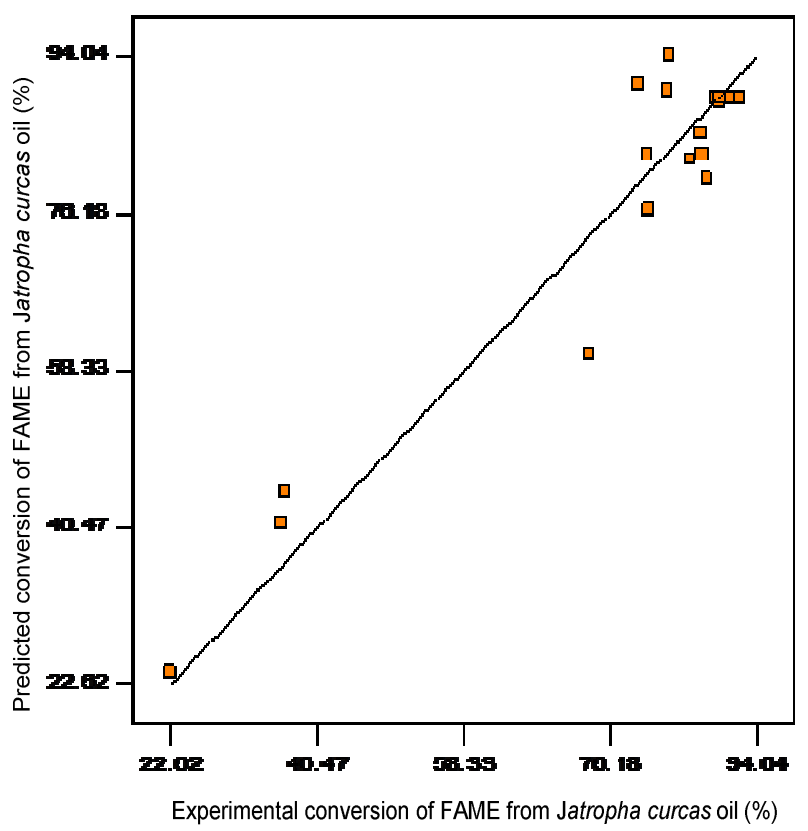

Fig. 1 - Predicted versus experimental conversion of JCO FAME. 
TABLE VI

ANALYSIS OF VARIANCE (ANOVA) FOR THE REGRESSION MODEL EQUATION AND COEFFICIENTS AFTER ELIMINATING INSIGNIFICANT TERMS

\begin{tabular}{|l|c|c|c|c|c|}
\hline Source & $\begin{array}{c}\text { Sum of } \\
\text { square }\end{array}$ & $\begin{array}{c}\text { Degree } \\
\text { of } \\
\text { freedom }\end{array}$ & $\begin{array}{c}\text { Mean of } \\
\text { squares }\end{array}$ & F-test & $\begin{array}{c}\text { Probability } \\
(\mathrm{P})>\mathrm{F}\end{array}$ \\
\hline Model & 7320.51 & 9 & 813.39 & 11.67 & $<0.0001^{* *}$ \\
\hline $\mathrm{x}_{2}$ & 3148.05 & 1 & 3148.05 & 45.18 & $<0.0001^{* *}$ \\
\hline $\mathrm{X}_{3}$ & 907.06 & 1 & 907.06 & 13.02 & $<0.0001^{* *}$ \\
\hline $\mathrm{x}_{2}{ }^{2}$ & 2186.26 & 1 & 2186.26 & 31.38 & $<0.0001^{* *}$ \\
\hline $\mathrm{x}_{2} \mathrm{X}_{3}$ & 942.43 & 1 & 942.43 & 13.53 & $<0.0001^{* *}$ \\
\hline Residual & 696.79 & 10 & 69.68 & & \\
\hline
\end{tabular}

** Significant at $1 \%$ level.

Bajpay and Tyagi reported that the conversion rate increase with time, but the conversion were almost the same after $1 \mathrm{~h}$ transesterification of soybean, beef tallow and sun flower [44]. Insignificant effect of reaction time caused by the observed reaction time in this study ranged from 60 mins-120 mins.

The quadratic term of $\left(\mathrm{x}_{2}\right)$ was significant for the yield of JCO FAME. The other significant terms include the effect of interaction between variables, particularly between variables $\left(x_{2}\right)$ and $\left(x_{3}\right)$. The results in Table 6 illustrate that there is a great possibility in improving the yield of JCO FAME with proper selection of transesterification process variables using $\mathrm{CaO}$ as the catalyst.

The interaction terms with a significant effect on the yield of JCO FAME was found to be the product of $\mathrm{x}_{2}$ and $\mathrm{x}_{3}$. Fig. 2 and Fig. 3 shows the changes in yield with varying methanol/oil ratio at $0.75 \%$ and $1.25 \%$ catalysis. It is generally perceived that higher methanol/oil ratio used will result in higher yield of FAME because increasing methanol shifts the equilibrium towards the products [43]. However, the effect of methanol/oil ratio on the yield of FAME was significantly different at different amount of catalyst.

The yield of FAME was increased at $0.75 \%$ catalysis if compared to $1.25 \%$ according to the data in Fig.2 and 3.A more probable reason for lower activity of $1.25 \% \mathrm{CaO}$ compared to $0.75 \%$ is that the catalyst (produced from a crude lime stone) contains some impurities which hinder the reaction or deactivate $\mathrm{CaO}$ when reaching some critical level. The FAME yield could be improved by introducing excess amounts of methanol to shift the equilibrium to the righthand side. The experimental results, illustrated in Fig. 3, indicate the molar ratio of methanol to oil has a significant impact on the FAME yield. The FAME yield increased from $42 \%$ to $94 \%$ when the molar ratio was increased from $7: 1$ to $11: 1$ at $1.25 \%$ catalysis. In comparison, the FAME yield was $80 \%$ at a $7: 1$ molar ratio of methanol to oil at $0.75 \%$ catalysis. However, the yields were slightly reduced when the ratio of methanol to oil was higher than 10:1, and the biodiesel yield was only $88 \%$ at $11: 1$. The reason is that the catalyst content decreased with increase of methanol content. Therefore, the optimum molar ratio of methanol to oil depends on amount of catalyst loaded [31]

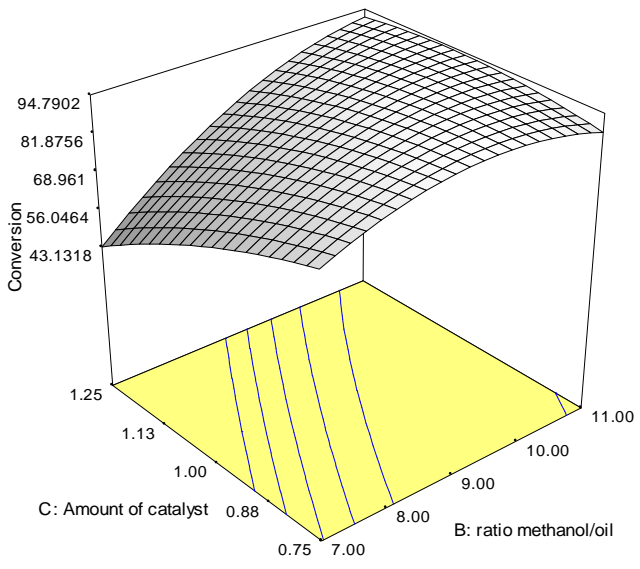

Fig. 2 - Response Surface Plot of Effect of methanol oil ratio and amount of catalyst on the conversion of JCO to FAME

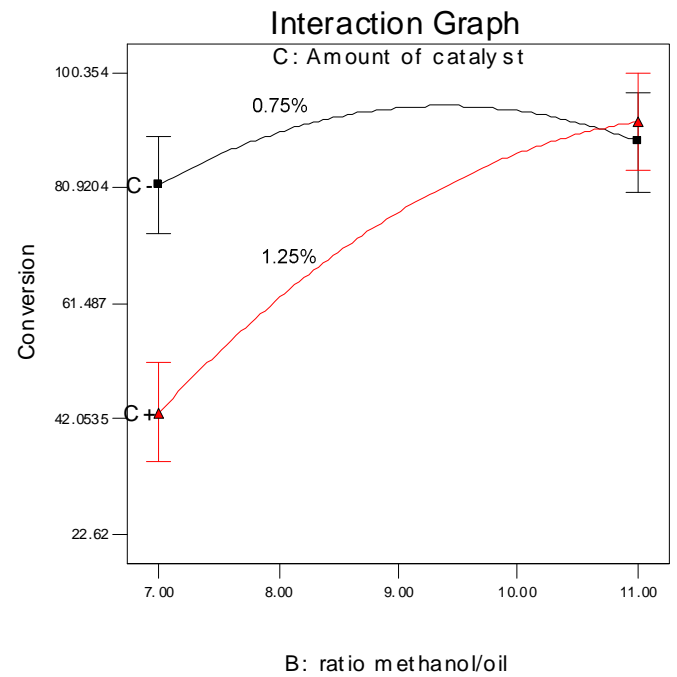

Fig. 3 - Two dimensional drawing on effect of methanol oil ratio and amount of catalyst on the conversion of JCO to FAME

\section{Purification of as-synthesized FAME}

When calcium oxide is used for the transesterification of vegetable oil with methanol, it is very likely that the reaction is catalyzed not only by basic sites on the surface but also by soluble substance from the solid base catalyst [45]. When basic catalyst is employed to prepare FAME, some cations will remain in the products. Because of the leaching of the solid base catalyst, purification of the produced FAME must be carried out. It is found that strong acidity is one of the desirable properties for the cation-exchange resin to remove the soluble substance [46].

Water washing is not suitable for purifying $\mathrm{CaO}$-catalyzed FAME. The operability of the purifying process is poor if water is used and the effect of the purifying is not obvious if the stirring speed is too low. Contrarily, too high stirring speed leads to emulsification. The yield of the product is decreased and a large amount of the product is lost and the quality of the product cannot meet the standard of FAME [29]. The strategy for purifying the as-synthesized FAME using bentonite $(2.5 \%$ of mass fraction) was employed as 
complexing agents to remove calcium ions in this study. Six methods for the purification step in FAME production were compared: (A) adsorption on bentonite; (B) adsorption on $\mathrm{HCl}$-activated bentonite; (C) adsorption on $\mathrm{HCl}$-activated and calcinated at $500{ }^{\circ} \mathrm{C}$ bentonite (D) adsorption on $\mathrm{H}_{2} \mathrm{SO}_{4^{-}}$ activated bentonite; (E) adsorption with $\mathrm{H}_{2} \mathrm{SO}_{4}$-activated and calcinated at $500{ }^{\circ} \mathrm{C}$ bentonite; (F) adsorption on citric acid (1.5\% of mass fraction); and (G) without adsorption. The results are listed in Table 7.

As shown in Table 7, the application of $\mathrm{H}_{2} \mathrm{SO}_{4}$-activated bentonite resulted in best removal for the soluble substance, which was reflected by the calcium content remaining after purification. $\mathrm{H}_{2} \mathrm{SO}_{4}$-activated bentonite has a better efficiency than $\mathrm{HCl}$-activated bentonite caused by the higher surface area and pore volume (Table 3). Since $\mathrm{H}_{2} \mathrm{SO}_{4}$ activated bentonite is more porous than the other adsorbent, it is best suitable for removal of the soluble substance. The performace of this adsorbent is similar to citric acid, a complexing agent which was also previously used by Zhu et al [29].

The acid-activated and calcinated bentonite method can also remove the calcium ions in the as-synthesized FAME containing 1,666. $67 \mathrm{mg} / \mathrm{ml}$ of $\mathrm{Ca}^{2+}$, but the yield of the purified biodiesel is low. The probable reason is that surface and pore properties of the acid-activated and calcinated bentonite was lower than acid-activated bentonite without calcinations (Table 3 ). In summary, acid-activated and calcinated bentonite is not suitable for decalcifying agent.

It was interesting to note that, even though the surface area and pore properties of non-activated bentonite was lower than $\mathrm{H}_{2} \mathrm{SO}_{4}$-activated bentonite, the decalcification efficiency was unsignificantly different. The probable reason is that beside surface and pore properties, CEC is also a desirable properties for FAME purification. CEC of the raw and acid treated bentonite showed that they vary with the concentration and and type of activating acid. CEC also followed the same trend as the acidity. The optimum condition $(\mathrm{pH})$ from previous study for higher CEC is 3.72 for $\mathrm{H}_{2} \mathrm{SO}_{4}$-activated bentonite and 3.82 for $\mathrm{HCl}$-activated bentonite [46].

Even though decalcification efficiency between $\mathrm{H}_{2} \mathrm{SO}_{4}$ activated bentonite and non-activated bentonite was nonsignificantly different, the remaining calcium was different significantly. Non-activated bentonite has remaining calcium was higher than $\mathrm{H}_{2} \mathrm{SO}_{4}$ activated bentonite (Table 7). During the experiments, it was observed that when nonactivated bentonite was used, the density of the purified biodiesel obtained still higher than standard of FAME. Therefore, the non-activated bentonite method is not suitable for our purification process.

Beside the increasing of FAME yield and decalcification rate, the application of $\mathrm{H}_{2} \mathrm{SO}_{4}$-activated bentonite for purification is also environmentally friendly compared to water washing methods where a large amount of water is needed. The volume ratio of oil to water should be $2: 1-5: 1$, which is inevitable to produce a huge of polluted water [29].
TABLE VII

DECALCIFICATION EFFICIENCY OF DIFFERENT TYPE OF PURIFICATION METHOD

\begin{tabular}{|c|c|c|c|c|}
\hline Code & $\begin{array}{l}\text { Purification } \\
\text { Method }\end{array}$ & $\begin{array}{l}\text { Remaining } \\
\mathrm{Ca}^{2+} \\
\mathrm{L}) \quad(\mu \mathrm{L} /\end{array}$ & $\begin{array}{l}\text { Decalcificati } \\
\text { on efficiency } \\
(\%)\end{array}$ & $\begin{array}{l}\text { Yield } \\
(\%)\end{array}$ \\
\hline D & $\begin{array}{l}\mathrm{H}_{2} \mathrm{SO}_{4} \text {-activated } \\
\text { bentonite }\end{array}$ & $92.37^{\mathrm{a}}$ & $94.57^{\mathrm{a}}$ & $92.50^{\mathrm{a}}$ \\
\hline $\mathrm{F}$ & Citric acid & $93.49^{a}$ & $93.51^{\mathrm{a}}$ & $92.27^{\mathrm{a}}$ \\
\hline A & $\begin{array}{l}\text { Non-activated } \\
\text { bentonite }\end{array}$ & $112.37^{b}$ & $93.46^{\mathrm{a}}$ & $91.69^{\mathrm{ab}}$ \\
\hline B & $\begin{array}{l}\mathrm{HCl} \text {-activated } \\
\text { bentonite }\end{array}$ & $213.88^{c}$ & $88.46^{\mathrm{b}}$ & $85.30^{\mathrm{c}}$ \\
\hline $\mathrm{E}$ & $\begin{array}{l}\mathrm{H}_{2} \mathrm{SO}_{4} \text {-activated } \\
\text { and calcinated } \\
\text { bentonite }\end{array}$ & $272.57^{d}$ & $83.67^{d}$ & $81.20^{\mathrm{d}}$ \\
\hline $\mathrm{C}$ & $\begin{array}{l}\mathrm{HCl} \text {-activated } \\
\text { and calcinated } \\
\text { bentonite }\end{array}$ & $290.58^{\mathrm{e}}$ & $85.49^{c}$ & $80.38^{\mathrm{e}}$ \\
\hline $\mathrm{G}$ & Control & $1666.67^{f}$ & & \\
\hline
\end{tabular}

Values with similar superscripts in a column do not deffer significantly $(\mathrm{p} \leq 0.05)$

\section{Fuel properties of jatropha FAME}

Several key properties of the purified biodiesel have been characterized, and the results are shown in Table 8. Most of the properties of the purified biodiesel meet the criteria of Indonesian standard (SNI- 04-7182-2006), Indian standard (IS 15607 : 2005), Germany standard (DIN E 51606) and USA standard (ASTM D6751-02), except for the slightly lower purity of FAME at optimized condition (94.35\%). An European standard (EN 14214) require the FAME purity of $96.5 \%$, but Germany standard ( DIN E 51606) and USA standard (ASTM D6751-02) contains no such restriction (Table 8).

TABLE VIII

FUEL PROPERTIES OF JATROPHA FAME

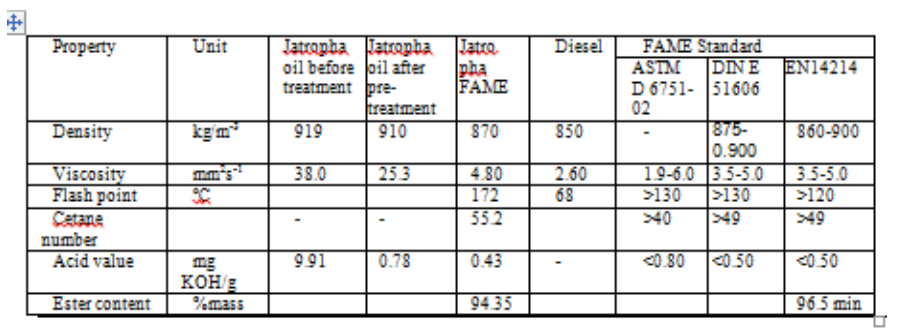

\section{CONCLUSIONS}

Based on the experimental results obtained, it can be concluded that $\mathrm{CaO}$ could be used as an effective catalyst for the conversion of JCO to FAME. The optimized critical values were found to be 79.33 minutes reaction time, 10.41:1 methanol:oil molar ratio and $0.99 \%$ mass fraction of catalyst at reaction temperature of $65^{\circ} \mathrm{C}$. Among bentonites used for purification, $\mathrm{H}_{2} \mathrm{SO}_{4}$-activated bentonite shows the best performance, resulting in the yield of jatropha FAME above $90 \%$, with properties satisfying the standard for FAME. The whole process is simple and seems promising for practical application. 


\section{ACKNOWLEDGMENT}

The authors would like to thank Directorate General of Higher Education of Republic of Indonesia for the Competitive Research Grant No. 437/SP2H/PP/DP2M/ V/2009 and Universiti Kebangsan Malaysia for Research Grant UKM-GUP-NBT-08-27-113 and for all facilities which was used in this research.

\section{REFERENCES}

[1] Huber GW. Iborra S, Corma A. Synthesis of transportation fuels from biomass: chemistry, catalysts, and engineering. Chem Rev 2006; 106: 4044-98.

[2] Kulkarni MG, Dalai AK. Waste cooking oils an economical source for FAME: a review. Industrial Engin Chem Res. 2006; 45: 290113.

[3] Meher LC, Sagar VD, Naik SN. Technical aspects of FAME production by transesterification-a review. J Renew Sustain Energy Rev 2006; 10:248-68.

[4] Canakci M. The potential of restaurant waste lipids as FAME feedstocks, Bioresource Technol 2007; 98: 183-190.

[5] Ma F, Hanna MA. FAME production: a review. Bioresource Technol 1999; 70: 1-15.

[6] Kumar A, Sharma S. An evaluation of multipurpose oils seed crop for industrial uses (Jatropha curcas L.): a review. Ind Crops Prod 2008; 28:1-10.

[7] Singh AK. Development of a heterogeneously catalyzed chemical process to produce FAME. 2008. A Dissertation Submitted to the Faculty of Mississippi State University. USA.

[8] Fukuda H, Kondo A, Noda H. FAME fuel production by transesterification of oils. Biosci Bioengin 2001;92:405-16.

[9] Van Gerpen J. FAME processing and production. Fuel Process Technol 2005;86: 1097-107.

[10] Demirbas A. Progress and recent trends in biofuels. Progress in Energy and Combustion Sci 2007;33:1-18.

[11] Kawashima A, Matsubara K, Honda K. Development of heterogeneous base catalysts for FAME production. Bioresource Technol 2008; 99: 3439-43.

[12] Kansedo J, Lee KT, Bhatia S. FAME production from palm oil via heterogeneous transesterification. Biomass Bioenergy 2009; 33:271-76.

[13] Xie W, Huang X. Synthesis of FAME from soybean oil using heterogeneous $\mathrm{KF} / \mathrm{ZnO}$ catalyst. Catal Letters 2006; 107:1-2.

[14] Liu X, He H, Wang Y, Zhu S. Transesterification of soybean oil to FAME using $\mathrm{SrO}$ as a solid base catalyst. Catal Commun 2007;8:1107-11.

[15] Yang Z, Xie W. Soybean oil transesterification over zinc oxide modified with alkali earth metals. Fuel Processing Technol 2007;88:631-8.

[16] Granados ML, Poves MDZ, Alonso DM, Mariscal R, Galisteo FC, Moreno-Tost R, Santamaría J, Fierro JLG. FAME from sunflower oil by using activated calcium oxide. Appl Catal B: Env 2007;73:317-26.

[17] Kim HJ, Kang BS, Park YM, Kim DK, Lee JS, Lee KY. Transesterification of vegetable oil to FAME using heterogeneous base catalyst. Catal Today 2004;93-95:315-20.

[18] Ferreira DAC, Meneghetti MR, Meneghetti SMP, Wolf SR. Methanolysis of soybean oil in the presence of tin (IV) complexes. Appl Catal A: Gen 2007;317:58-61.

[19] Xie W, Li H. Alumina-supported potassium iodide as a heterogeneous catalyst for FAME production from soybean oil. J Mol Catal A: Chem 2006; 255:1-9.

[20] Xie W, Peng H, Chen L. Transesterification of soybean oil catalyzed by potassium loaded on alumina as a solid-base catalyst. Appl Catal A: Gen 2006;300:67-74.

[21] Suppes GJ, Dasari MA, Doskocil EJ, Mankidy PJ, Goff MJ. Transesterification of soybean oil with zeolite and metal catalysts. Appl Catal A: Gen 2004; 257: 213-23.

[22] Shibasaki-Kitikawa N, Honda H, Kuribayashi H, Toda T, Fukumura $\mathrm{T}$, Yonemoto T. FAME production using anionic ion-exchange resin as heterogeneous catalyst. Bioresource Technol 2007;98:416-21.
[23] Lo'pez DE, Goodwin JJG, Bruce DA. Transesterification of triacetin with methanol on Nafion_acid resins. J Catal 2007;245:381-91.

[24] AM, Vital J. Transesterification of soybean oil over sulfonic acid functionalised polymeric membranes. Catal Today 2006;118:16671.

[25] Dube MA, Tremblay AY, Liu J. FAME production using a membrane reactor. Bioresource Technol 2007;98: 639-47.

[26] Ranganathan SV, Narasimhan SL, Muthukumar K. An overview of enzymatic production of FAME. Bioresource Technol 2008;99(10):3975-81.

[27] Chantrell DG, Gillie IJ, Wilson K. Structure-ractivity correlation inMgAI hydrotalcite catalyst for FAME synthesis. Appl Catal: A Gen 2005;287: 183-90.

[28] Bournay L, Casanave D, Delfort B, Hillion G, Chodorge JA. New heterogeneous process for FAME production: a way to improve the quality and the value of the crude glycerin produced by FAME plants. Catal Today 2005;106: 190-2.

[29] Zhu H, Wu Z, Chen Y, Zhang P, Duan S, Liu X, Mao Z. Preparation of FAME Catalyzed by Solid Super Base of Calcium Oxide and Its Refining Process. Chinese J Catal 2006; 27: 391-96.

[30] Zabeti M, Daud WMAW, Mohamed Kheireddine Aroua MK. Activity of solid catalysts for FAME production: A review. Fuel Process Technol 2009; 90:770-77

[31] Liu, X., H. He, Y. Wang, S. Zhu, X. Piao. Transesterification of soybean oil to FAME using $\mathrm{CaO}$ as a solid catalyst. Fuel 2008; 87: 216-21.

[32] Kouzu M, Yamanaka S, Kasano T, Tajika M, Hidaka J. Calcium oxide as a solid base to catalyze transesterification of vegetable oil with methanol, for FAME production. Catal Catal 2007; 49:87-89.

[33] Kouzu M , Kasuno T , Tajika M, Sugimoto Y, Yamanaka S, Hidaka J. Calcium oxide as a solid base catalyst for transesterification of soybean oil and its application to FAME production. Fuel 2008; 87: 2798-806.

[34] Kouzu M, Yamanaka S, Hidaka J, Tsunomori M. Heterogeneous catalysis of calcium oxide used for transesterification of soybean oil with refluxing methanol. Appl Catal A: Gen 2009; 355: 94-99.

[35] Granados ML, Zafra Poves MD, Alonso M, Mariscal R, Galisteo FC, Moreno-Tost R, Santamarı́a J, Fierro JLG.FAME from sunflower oil by using activated calcium oxide. Appl Catal B: Env 2007; 73: 317-26.

[36] Demirbas A. FAME from sunflower oil in supercritical methanol with calcium oxide. Energy Conversion Manag 2007; 48: 937-41

[37] Veljkovic' VB, Stamenkovic'OS, Todorovic'ZB, Lazic 'ML, Skala DU. Kinetics of sunflower oil methanolysis catalyzed by calcium oxide. Fuel 2009; 88: 1554-62.

[38] Kawashima A, Matsubara K, Honda K. Acceleration of catalytic activity of calcium oxide for FAME production. Bioresource Technol 2009; 100: 696-700.

[39] Yan S, Lu H, Liang B. Supported $\mathrm{CaO}$ Catalyst Used in Transesterification of Rapeseed Oil for the Purpose of FAME Production. Energy Fuel 2008; 22: 646-51.

[40] Umdu ES, Tuncer M, Seker E. Transesterification of Nannochloropsis oculata microalga's lipid to FAME on $\mathrm{Al}_{2} \mathrm{O}_{3}$ supported $\mathrm{CaO}$ and $\mathrm{MgO}$ catalysts. Bioresource Technol 2009; 100: 2828-31.

[41] Kouzu M , Hidaka JS, Komichi Y, Nakano H and Yamamoto M. A process to transesterify vegetable oil with methanol in the presence of quick lime bit functioning as solid base catalyst. Fuel 2009; 88: 1983-90.

[42] Tiwari, AK, Kumar A, Raheman A. FAME production from jatropha oil (Jatropha curcas) with high free fatty acids: an optimized process. Biomass Bioenergy 2007;31:569-75.

[43] Kulkarni MG, Dalai AK. Waste cooking oil-an economical source for FAME production: a review. Indian Engin Chem Res 2006:45:2901-13

[44] Bajpay D, Tyagi VK. Biodiesel: Source, Production, Composition, Properties and Its Benefit. J Oleo Sci 2006; 55: 487-502.

[45] Granadoz GM, Poves MDZ, Alonso DM, Mariscal R, Galisteo FC, Moreno-Tost R, Santamaria J, Fierro JLG. FAME from sunflower oil by using activated calcium oxide Appl Catal B: Env 2007;73:317-26.

[46] Pushpaletha P, Rugmini S, Lalithambika M. Correlation between surface properties and catalytic activity of clay catalysists. Appl Clay Sci 2005; 30:141-53. 